와우이식 I

서울대학교 의과대학 이비인후과학교실

장 선 오.이 효 정

\title{
Cochlear Implantation I
}

Sun 0 Chang, MD and Hyo Jeong Lee, MD

Department of Otolaryngology-Head and Neck Surgery, Seoul National University, College of Medicine, Seoul, Korea

\section{서 론}

현재 우리 사회에서는 인구의 $0.44 \%$ 에 달하는 사람들 이 $40 \mathrm{~dB}$ 이상의 난청으로 고통받고 있으며, 약 $0.1 \%$ 인 43,000 명은 $80 \mathrm{~dB}$ 이상의 고도난청이나 전농으로 와우이식술의 잠정적인 적응이 되고 있다. 뿐만 아니라 태어나는 아기의 1,000 명당 1 명은 양측의 고도 이상의 난청아로 태어난다. 통계청의 자료에 따르면 2001년에 출생한 신생아가 약 60 만명이므로 1년에 약 600 명 정 도의 고도난청 신생아가 태어나는 셈이다. 특히 유소아 기의 정상청력은 교육과 지능 및 언어발달에 필수적이라 는 점에서 성인보다 중요성이 더욱 크다고 할 수 있다.

와우이식술은 보청기를 써도 도움을 받지 못하는 양 측 고도감각신경성 난청환자들에게 청력을 제공할 수 있는 방법으로, 외부의 음원으로부터 전달된 소리에너지 를 내이를 대신하여 전기에너지로 변환시키고 와우 내 에 삽입된 전극을 통하여 청신경을 직접 자극하여 소리 를 들을 수 있도록 하는 술식이다. 즉 단순히 소리를 증 폭시키는 보청기와는 달리 전극을 통해 와우에 주파수 별로 특이적인 신호를 제공하게 되어 환자들은 자음의 분별에 필요한 정보를 얻을 수 있고 환경음과 언어를

교신저자 : 장선오, 110- 799 서울 종로구 연건동 28번지 서울대학교 의과대학 이비인후과학교실 전화 :(02) 760- 3649. 전송 :(02) 745- 2387 E-mail : suno@snu.ac.kr
구별할 수 있게 된다.

그러나, 고도 난청환자들이 모두 와우이식의 대상이 되는 것은 아니다. 정도에 따라 적절한 보청기로 학습과 생활에 잘 적응하고 있는 환자들도 많이 있으므로 이런 경우는 와우이식의 적응이 되지 않는다. 보청기로 도움 이 되지 않는 환자들을 선별할 수 있는 잘 고안된 검사 프로토콜을 사용하여 와우이식의 수술 전 평가와 대상 자 선정이 이루어져야 한다.

현재 와우이식은 보청기로도 도움을 받을 수 없는 고 도의 감각신경성 난청의 치료에 있어 유일하게 도움을 줄 수 있는 재활치료법으로 공인 받아 왔다. 1988년부 터 국내에서 시행되고 있으며 여러 센터에서 1,000명 이상의 환자들이 와우이식의 혜택을 받았고, ${ }^{1)}$ 전세계 적으로 60,000 명 이상의 환자들이 와우이식을 이식 받 았고 그 수는 계속 증가하고 있다.

\section{와우이식 대상환자의 선정}

와우이식은 양측 귀에 고도의 감각신경성 난청이 있 고 보청기로 적절한 기간동안 청력 재활을 하여도 효과 가 없는 경우 적응된다. 즉, 와우이식을 하였을 때 얻을 수 있는 이득이 보청기로 얻는 이득보다 클 때 시행한 다. 그러나 청신경이 기능을 하고 있음이 증명되어야 하 며, 전신마취나 수술에 금기가 될 내과적, 신경과적, 정 신과적 문제가 없고, 환자와 보호자가 수술에 대한 강한 동기를 가지고 있을 때 수술을 시행한다. 
Table 1. Cochlear 사의 Nucleus 24 contour 적응기준

\begin{tabular}{|c|c|}
\hline 연 령 & 기 \\
\hline 유아 12- 24개월 & $\begin{array}{l}\text { 4양쪽 귀의 심도 감각 신경성 난청 }(\geq 90 \mathrm{~dB}) \\
\text { 4듣기 능력의 발달이 더딘 겨우 }\end{array}$ \\
\hline 소아 2- 5세 & $\begin{array}{l}\text { 4양쪽 귀의 고도, 심도 감각신경성 난청 }(\geq 70 \mathrm{~dB}) \\
\text { 4MLNT (Multisylable Lexical Neighborhood Test) } \leq 30 \% \\
\text { 4듣기 능력의 발달이 더딘 경우 }\end{array}$ \\
\hline 소아 5- 18세 & $\begin{array}{l}\text { 4양쪽 귀의 고도, 심도 감각신경성 난청 }(\geq 70 \mathrm{~dB}) \\
\text { 4NT ( Lexical Neighborhood Test) } \leq 30 \% \\
\text { 4듣기 능력의 발달이 더딘 경우 }\end{array}$ \\
\hline 성인 18세 이상 & $\begin{array}{l}4 \text { 양측 귀의 중등도 이상 감각신경성 난청 ( 저주파수에서 } \geq 40 \mathrm{~dB} \text {, 중등 및 고주파수에서 } \geq 90 \mathrm{~dB} \text { ) } \\
4 \text { 수술할 귀로만 들을 때 HINT ( Hearing in Noise Test) } \leq 50 \% \text {, 좋은 쪽 귀로만 듣거나 양쪽귀로 들을 } \\
\text { 때 HINT } 60 \%\end{array}$ \\
\hline
\end{tabular}

Table 2. Advanced bionic사의 Clarion 적응기준

\begin{tabular}{|c|c|}
\hline 연 령 & 준 \\
\hline 소아 12개월-4세 & $\begin{array}{l}\text { 4양측 귀의 고도 감각신경성 난청 }(\geq 90 \mathrm{~dB}) \\
\text { 4최소한 3- 6개월의* 보청기 사용 후 듣기 능력의 발달이 더디거나 } \mathrm{MLNT} \leq 20 \%\end{array}$ \\
\hline 소아 4세-18세 & $\begin{array}{l}\text { 4양측 귀의 고도 감각신경성 난청 ( } \geq 90 \mathrm{~dB} \text { ) } \\
\text { 4최소한 3- 6개월의 보청기 사용 후 PBK (Phonetically Balanced-Kindergarten Test) } \\
\leq 12 \% \text { 혹은 HINT } 30 \%\end{array}$ \\
\hline 성인 18세 이상 & $\begin{array}{l}\text { 4양측 귀의 중등도 이상 감각신경성 난청 ( } \geq 70 \mathrm{~dB}) \\
\text { 4후언어기 농 } \\
\text { 4적절히 보정된 보청기를 낀 상태에서 } \mathrm{HINT} \leq 50 \%\end{array}$ \\
\hline
\end{tabular}
*:12- 23개월 ; 3개월 이상, 2- 17세 ; 6개월 이상 보청기 사용. 방사선학적 검사상 와우 골화가 의심되는 경우 이 기간 기 준은 철회됨

보다 발전된 새로운 와우이식기가 개발될 때마다 와 우이식의 적응증은 점점 넓어지고 있다. 와우이식의 초 기에 청각학적 적응기준은 순음청력역치가 $100 \mathrm{~dB}$ 이상, 어음명료도치 $0 \%$ 였으나 지금은 순음청력역치 $70 \mathrm{~dB}$ 이 상, 어음명료도치 $30 \%$ 미만까지로 완화되었고 점차 완 화되는 추세이다. 보통 18세를 기준으로 소아와 성인으 로 구분하고, 초기에는 주로 성인이 그 대상이였으나 현 재는 1 세 미만의 유아까지 그 대상범위가 확대되었다. Nucleus사의 Contour 전극 제품은 12 개월부터의 시술 이 가능하다고 미국 FDA 의 공인을 받았고 6개월 된 환 아에서의 와우이식도 보고되었다. 와우이식기를 개발하 는 회사가 자사 제품에 대해 제시하는 적응증을 $\mathrm{T}$ able 1과 T able 2에 제시하였다. ${ }^{2)}$

청각학적 기준 뿐 아니라 환자의 사회적 환경 또한 중요한 요소가 된다. 우선 환자 자신과 환자의 가족이 술 후 재활 치료에 적극적이고, 와우이식술과 술 후 결 과에 대해 충분히 이해하고 있어야 하며 비현실적인 기 대를 갖지 않아야 한다. 또한 집에서 가까운 곳에 술 후
언어치료를 받을 수 있는 교육기관이 확보되어 있어야 한다. 우리나라에서는 와우이식술이 아직 의료보험의 혜 택을 받지 못하므로 환자의 경제적 상황에 따라 사회사 업기관과의 연계가 필요하기도 하다.

\section{내이기형}

현재에 와서는 와우무형성증과 와우신경 무형성증 외 에는 금기증이 되는 내이기형은 없다. 와우무형성증은 수 술전 측두골CT 로 확인할 수 있고 와우신경 무형성증은 측두골CT 에서 내이도가 현저히 좁을 때 의심하며 MRICISS영상과 와우각 전기자극검사Promontory stimulation test), 전기유발 청성 뇌간반응 검사(EABR)로 확인한다. 경도의 Mondini이형성증이나 전정도수관 확 장증(EVAS) 의 경우 술 후 청각수행력에서 내이기형이 없는 선천성 난청과 차이가 없다는 보고가 있으면) 와우저형성증이나 단일공동 기형 등 심한 내이기형에서 도 와우이식을 시행하여 좋은 결과를 얻은 증례들이 발 표되고 있다. 


\section{와우 골화}

와우 골화는 수술의 난이도로 인해 한 때 금기증으로 여겨지기도 하였으나 최근 와우 골화의 정도에 따라 적 용할 수 있는 여러가지 술기들이 발표되었다.5) 뇌막염 후 의 와우 골화는 기저회전의 고실계에서 와우도수관의 개 구부로부터 시작되므로 와우 기저회전의 하부분절에 국한 된 경우가 가장 많다. 이러한 경우 정원창에서 8 10 mm 거리까지 가는 드릴 버어 등으로 폐쇄골을 제거하여 개 방된 고실계에 전극을 삽입할 수 있고 술후 청각수행력 도 와우골화가 없는 경우와 비교하여 차이가 없다. ${ }^{67)}$

뇌수막염을 않은 뒤 와우 골화가 언제부터 시작되는가 는 와우이식의 시기를 결정하는데 중요하다. 확정된 가 설은 없으나 뇌수막염을 않은 후 2 3개월 후에 방사선 학적 검사상 와우 골화를 보이는 경우들이 보고되었으며, 인위적으로 뇌수막염을 유발시킨 동물실험에서는 뇌수 막염후 3주째부터 와우 골화가 시작되었으며 12개월째 에도 계속 골화가 진행되었다. ${ }^{8)}$ 뇌막염후 난청의 경우 가능한 빠른 시기에 측두골CT 등 방사선학적 검사를 시 행하며 와우 골화가 진행되기 전에, 연령이 12 개월 이전 이라도 조기에 와우이식을 시행한다. ${ }^{9}$

\section{증후군질환자, 인지능력/운동능력 발달 이상 등 다중신체 장애자}

난청 이외의 다른 신체장애가 동반된 환자의 경우 수 술 후 재활치료가 어려워 청능이나 언어능력의 발달이 느려질 수 있으나 경우에 따라 와우이식 수술로 충분한 이득을 얻을 수 있다. 이 경우 환자 보호자와 이비인후 과의사, 청각사, 언어치료사, 정신과의사 등 와우이식팀 내에서의 의견조율이 먼저 이루어져야 한다. ${ }^{10)}$

\section{수술전 검사}

\section{병력 및 전신검사}

' 소리에 반응이 없다' 든지' 언어발달이 늦다' 는 문제

를 주소로 이비인후과 외래를 내원하는 경우나 돌발성 혹은 진행성 난청을 주소로 오는 모든 난청환자들에 대 해서는 자세한 병력을 기록하고 난청을 초래할 수 있는 과거력 및 가족력을 집중적으로 물어보아야 한다. 이과 적인 병력과 이학적 검사 소견도 매우 중요하여 외이와
중이에 활동성 감염이 있는지 고막 천공이 있는지 중이 나 유양동의 수술을 받은 적이 있는지 검사하여야 한다. 고도 난청 소아환자에서는 정상인보다 시각장애의 빈도 가 높으므로 안과적 검진을 의뢰한다. 또한 전신마취와 수술 자체에 위험요인이 되는 전신질환이 없는지 검사 한다.

\section{청력검사}

고도 및 심도의 양측성 청각장애의 진단은 순음청력검 사(pure tone audiometry), 뇌간유발반응검사 (auditory brainstem response test), 언어청력검사 (speech audiometry) 를 통하여 이루어진다. 연령이 어린 어린이의 경우 뇌간 유발반응검사를 하며 또한 전도성 청각장애 (conductive hearing impairment) 가 함께 동반되어 있 는지를 검사하기 위하여 임피던스 청력검사를 실시한다. 3 4세의 어린이의 경우는 놀이를 통한 청력검사 play audiometry) 를 시행한다.

고도난청 이상의 청력소실을 가진 환자에게 모두 와 우이식을 하지는 않는다. 우선 잘 맞는 보청기의 착용으 로 환자의 반응을 평가하여 잔여 청력의 정도를 판정하 는 것이 무엇보다 중요하다. 만일 보청기가 잘 맞지 않 던가 보청기 착용에 잘 적응하지 못하였으면 적절한 보 청기를 새로 착용케하여 소리를 습득하는 연습을 하게 한다. 이런 기간은 최소한 3 개월에서 6 개월 이상 지속 되어야 하며 충분히 적응되었다고 판단되면 다시 검사 하여 그간의 보청기를 이용한 청능훈련이 충분히 언어 발달에 영항을 주었는지를 평가한다. 즉 보청기를 통한 청력의 향상이 어느 정도 가능한지 평가하여 이 기간 동 안 소리에 대한 반응이 유의하게 향상될 경우 인공와우 수술은 재고된다. 전언어기(prelingual) 소아들도 보청 기의 착용으로 느리지만 점진적인 보청기 효과를 보여 주기도 하지만 반응이 미비할 경우는 청각학적인 관점 으로 볼 때 일단 와우이식의 대상이 된다.

\section{언어평가}

이 평가의 목적은 대상자의 음에 대한 기능적인 사용 상태와 청각학적 정보를 얻기 위함이며, 향후 재활평가 의 기초자료를 제시한다. 언어지각검사는 언어수준과 인 지능력에 따라 환자마다 큰 차이를 보이는데 특히 소아 
에서 그 변이가 심하다. 검사방법으로는 우선 여러 개의 보기가 주어진 상태에서 검사하는 말소리 변별능력 검 사(closed- set speech perception test) 는 단어들의 음절수 변별능력, 문장의 길이 변별능력 등을 평가하고, 보기가 주어지지 않은 상태에서의 말소리 변별능력 검사 (open- set speech perception test) 는 단어와 문장을 어느 정도로 이해하는지를 평가한다. 아주 어린 소아인 경우에는 언어기 이전의 의사소통기술을 살펴보아야 한 다. 언어평가는 환자에 따라 결과가 다르게 나타나므로 연령, 난청발생시기, 지적발달정도 및 성장 환경이 고려 되어야 한다.

\section{신경전도로의 확인}

이식의 전제로 신경전달경로가 보존되어 있어야 하며 또 이식할 귀를 결정해야 하는데 이를 위해서 성인에서 는 와우각 전기자극검사(transtympanic promontory electric stimulation test) 를 시행하지만 10세미만의 소 아에서는 이 방법이 그리 용이하지 않아 전신마취하에서 전기유발 청성 뇌간반응 검사 transty mpanic electrically evoked ABR) 을 시도하기도 한다.

\section{영상검사}

술 전 측두골 고해상도 컴퓨터 단층촬영(HRCT )은 수 술 전 필수적인 검사로 여러가지 정보를 얻을 수 있다. 유양동의 함기화 정도, 안면신경 주행의 이상 유무, 고 경정맥구(high jugular bulb) 의 유무, 고실유양동격막의 상태를 미리 확인하여 수술시에 닥칠 수 있는 문제점에 대비한다. Mondini이형성증 등의 내이기형, EVAS같은 난청의 원인이 될 수 있는 여러가지 기형의 여부를 알 수 있다. 좁은 내이도는 청신경의 발생부전을 시사하므 로 내이도의 수직단면영상을 제공하는 MRI- CISS영상 으로 8번 뇌신경의 상태를 확인하여야 한다. 뇌수막염 후 난청인 경우 와우의 개방성(cochlear patency)을 관찰하여 와우이식의 방향을 결정할 수 있으며, MRI T 2- weighted image가 도움이 된다. 와우내강의 폐쇄 가 수술기법의 향상으로 더 이상 수술의 금기는 아니지 만 충분한 수의 전극을 삽입할 수 없는 경우가 있으며 이에 의한 술 후 효과를 보호자와 상의해야 한다.

\section{정신의학적 검사}

정신의학자는 인공와우 이식 대상자의 일반적인 인지 능력, 동기, 가족과 환자의 기대에 대하여 중요한 정보 를 제공한다. 실제로 일반적 지적수준을 평가하고 인공 와우 이식 후의 재활에 영향을 미치는 다른 문제점들을 파악하기 위하여 여러 검사를 시행한다. 가족들도 정신 의학자와 상담할 때는 다른 팀 구성원들에게 밝히지 않 았던 기대에 대하여 쉽게 토로하게 된다. 이러한 기대에 대하여 팀 구성원들은 가족들과 상담함으로서 이해를 도울 수 있다.

술 후 재활교육을 받기 위해서는 환자의 올바른 정신 상태가 중요하다. 전농과 연관되지 않은 심한 정신병이 나 정신신경증이 있으면 이식수술을 하여서는 안된다.

\section{뇌수막염 예방접종}

2002년 10월 FDA 의 발표에 따르면 전세계적으로 와 우이식 후 91예의 뇌수막염이 발생하였고 그 중 17예 가 사망하였다. 91예 중 56예가 Advanced Bionics사 의 기기로 수술을 받았고, 33예가 Nuclues사, 1예가 Med- El사의 기기로 수술을 받았다. 미국에서는 52예 의 뇌막염이 발생하였고 이 중 5 예가 사망하였다. 연령분 포를 보면 18개월에서 84세까지로, 그 중 33예(63\%) 가 7세 미만의 소아환자였다. 와우이식에서 증상 발생까지 의 기간은 수술 후 24 시간 이내에서 6 년 사이로, $2 \beta$ 에 서 1년 이내에 발병하였고, 대부분 수술 후 수주 이내에 발병하였다. 23예의 뇌척수액 배양 결과 Streptococcus pneumoniae가 16예, Hemophilus influenzae가 4예, Streptococcus viridans가 2예, Escherichia coli가 1 예에서 검출되었다.

와우이식 후 뇌수막염의 원인은 아직 명확히 밝혀지 지 않았으나 뇌수막염의 위험인자가 될 수 있는 내이기 형이 있는 경우, 뇌수막염의 병력이 있는 경우, 5 세 미 만의 소아, 중이염, 면역 결핍, 특정한 수술 술기 등이 위험인자로 생각되고 있다. 또한 Advanced Bionic사의 Clarion기기 전극을 삽입할 때 Positioner를 사용한 경 우 뇌수막염의 발생빈도가 높아 판매가 금지되었으나 인과관계는 명확히 밝혀지지 않았다. 
Table 3. 와우이식 대상자의 예방접종 (CDC), Oct 2002'11)

\begin{tabular}{|c|c|}
\hline \multicolumn{2}{|c|}{ Pneumococcal vaccination } \\
\hline$<2$ years & $\begin{array}{l}\text { 1) 7-valent pneumococcal conjugate vaccine (Prevnar }{ }^{\circledR} \text {; PCV7) : 2, 4, 6, } 12 \text { to } 15 \text { months에 } \\
\text { 접종 } \\
\text { 2) } 2 \text { 세가 지난 뒤 23-valent pneumococcal polysaccharide vaccine (Pneumovax }{ }^{\circledR} 23 \text { or Pnu- } \\
\text { Imune }{ }^{\circledR 23} \text {; PPV23) 1회 접종 }\end{array}$ \\
\hline 2- 5 years & $\begin{array}{l}\text { 1) 이전에 PCV7을 접종한 경우 : PPV23 1회 접종. 이때 마지막 PCV7 접종시기보다 최소한 2개 } \\
\text { 월이 지나야 한다. } \\
\text { 2) 이전에 PCV7을 접종하지 않은 경우 : PCV7을 2개월 간격으로 2회 접종하고 2개월 이상의 } \\
\text { 기간이 지난 뒤 PPV23 1회 접종 }\end{array}$ \\
\hline$>5$ years & PPV23 1회 접종 \\
\hline \multicolumn{2}{|c|}{ Hib ( Hemophilus influenza type b) vaccination } \\
\hline$<15$ months & $2,4,6,12$ to 15 months에 접종 \\
\hline 15 months - 5 years & 1회 접종 \\
\hline
\end{tabular}

Table 4. 와우이식대상자의 예방접종. Advisory Committee on Immunization Practices, 200312)

\begin{tabular}{clcc}
\hline Age at first PCV7 dose $(\mathrm{mos}){ }^{*}$ & PCV7 primary series & PCV7 additional dose & PPV23 dose \\
\hline $2-6$ & $\begin{array}{l}3 \text { doses, } \\
2 \text { months apart }\end{array}$ & $\begin{array}{c}\text { 1 dose at 12- 15 } \\
\text { months of age }\end{array}$ & $\begin{array}{c}\text { Indicated at } \geq 24 \\
\text { months of age }\end{array}$ \\
\hline 7- 11 & $\begin{array}{l}2 \text { doses, } \\
2 \text { months apart }\end{array}$ & $\begin{array}{c}\text { 1 dose at 12- 15 } \\
\text { months of age }\end{array}$ & $\begin{array}{c}\text { Indicated at } \geq 24 \\
\text { months of age }\end{array}$ \\
\hline 12- 23 & $\begin{array}{l}2 \text { doses, } \\
2 \text { months apart** }\end{array}$ & Not indicated & $\begin{array}{c}\text { Indicated at } \geq 24 \\
\text { months of age }\end{array}$ \\
\hline 2459 & $\begin{array}{l}\text { 2 doses, } \\
2 \text { months apart** }\end{array}$ & Not indicated & Indicated \\
\hline$\geq 60$ & Not indicated & Not indicated & Indicated \\
\hline
\end{tabular}

*: A schedule with a reduced number of total 7-valent pneumococcal conjugate vaccine (PCV7) doses is indicated if children start late or are incompletely vaccinated. Children with a lapse in vaccination should be vaccinated according to the catch-up schedule (CDC. Pneumoccocal conjugate vaccine shortage resolved. MMWR $2003 ; 52: 446-7$ )

$\dagger$ : For children vaccinated at age $<1$ year, minimum interval between doses is 4 weeks

$\ddagger$ : The additional dose should be administered $\geq 8$ weeks after the primary series has been completed

미국의 $\operatorname{CDC}($ Centers for Disease Control and Prevention) National Immunization Program에서 와우이 식 수혜자들을 대상으로 권고한 예방 백신 접종 지침을 T able 3과 T able 4에 제시하였다. ${ }^{11) 12)}$

뇌수막염의 예방접종이 효과적인 예방법이 될 수 있으 나 완전하지는 못하다. 미국의 와우이식 후 뇌수막염 증 례에서 뇌척수액 배양검사상 Strentococcus pneumonia 가 검출된 2예와 Haemonphilus influenzae가 검출된 2예는 이전에 적절한 예방접종을 받았던 예였다. 적절 한 예방접종과 함께 수술 시 철저한 무균원칙을 지키는 것이 중요할 것이다.

\section{와우이식 방향의 선택}

한쪽 귀가 청각학적으로 아무 반응이 없거나, 10년 이 상 사용하지 않았을 때는 반대쪽 귀를 선택한다. 양 귀 의 전농의 기간이 다르면 최근까지 사용된 귀 즉, 최근 에 전농이 된 귀를 선택한다. 양 귀 모두 보청기를 사용 하여도 도움을 받지 못하면 조금이라도 잔청이 남은 쪽 을 선택한다. 이는 나선신경절 세포가 좀더 기능하리라 생각되는 쪽을 선택하는 것으로 와우각 전기자극검사 (transty mpanic promontory electric stimulation test) 나 전기유발 청성 뇌간반응 검사 등의 검사를 시행하여 객관적인 검사결과를 비교하여 반응이 좋은 쪽 귀를 선 
택하기도 한다.

양 귀에 모두 잔청이 어느 정도 남아있으면 청력이 나 쁜 귀를 선택하여 와우이식을 시행하고 반대편에 보청기 를 계속 착용하여 양청이의 장점을 누릴 수 있다. 영상검 사상 와우골화나 내이기형, 안면신경기형이 있으면 좀더 정상에 가까운 귀를 선택한다. 외부에 착용되는 언어처 리기(speech processor)와 머리장치(headset)의 작동 을 용이하게 하기 위해 오른손잡이는 오른쪽을, 왼손잡

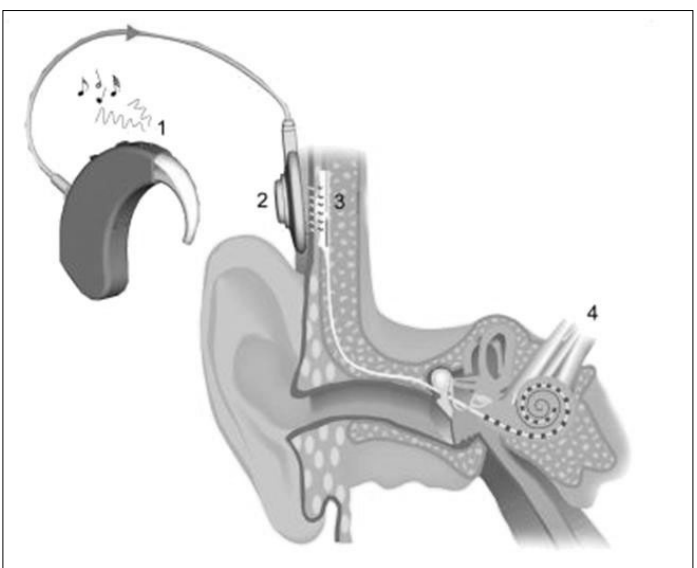

Fig. 1. Cochlear implant with BTE ( behind the ear) type speech processor. 1 : The microphone combined with the ear-level speech processor 2 : Antenna, 3 : Receiver/stimulator, 4. Intracochlear electrodes.
이는 왼쪽을 선택하기도 한다. 모든 조건이 같으면 오른 쪽에 시행한다. ${ }^{13)}$

\section{와우이식기의 구조와 종류}

청각생리에 대한 연구와 전기공학의 발전으로 와우이 식기는 발전을 거듭하여 현재의 시스템에 이르게 되었 다. 와우이식기는 기본적으로 외부(outer device) 에 착용 하는 송화기(microphone), 언어처리기(speech processor), 인테나(antenna), 그리고 수술로 인체 내에 삽입 하는(inner device) 수용/자극기(receiver/stimulator) 와 전극(electrode)의 두 부분으로 이루어져 있다. 와우 이식기를 통해 소리를 듣는 과정은 다음과 같다. 우선 송화기(microphone) 를 통해 소리에너지가 들어오면 언 어처리기(speech processor)로 가서 전기신호로 부호 화 되어진다. 부호화된 전기신호는 인테나를 통해 피부 를 경유하여 두개골 위에 삽입된 수용/자극기(receiver/ stimulator) 로 전달된다. 수용/자극기는 와우에 삽입된 전 극(electrode) 을 통해 전기 신호를 내보내 청신경을 자 극하고 뇌에서는 전기신호를 소리로 인지한다(Fig. 1).

현재 전세계적으로 20 여종의 와우이식기가 개발되어 있 으며 가장 널리 사용되고 있는 와우이식기는 호주 Cochlear 사의 Nucleus 24 series, 미국 Advanced Bionic사의

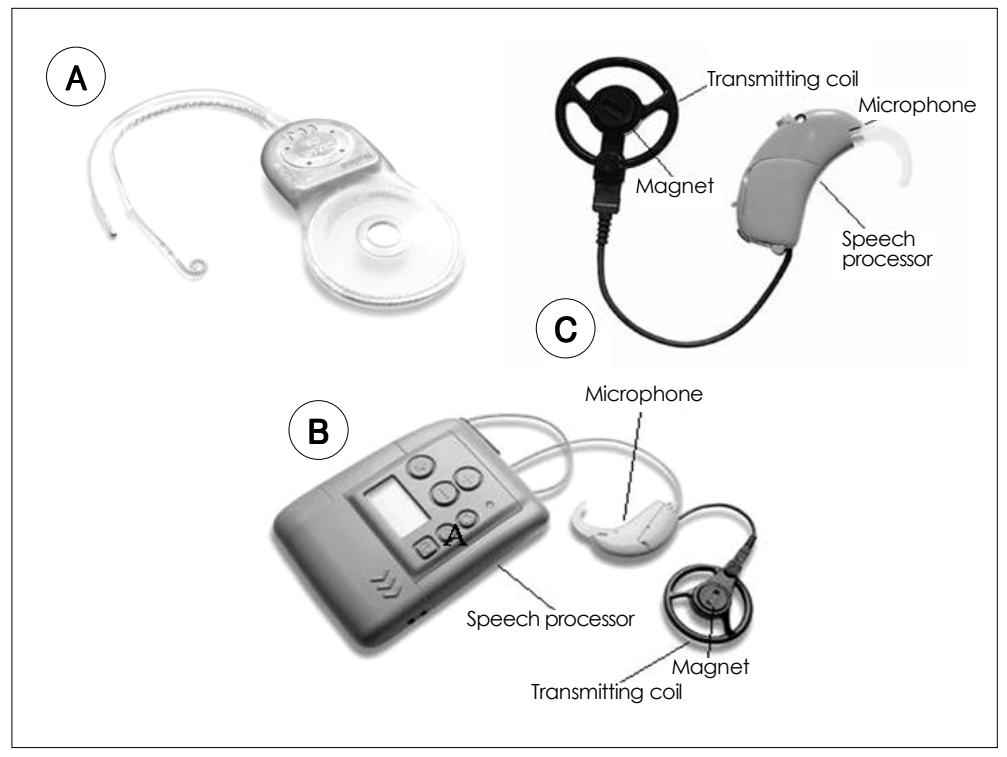

Fig. 2. Nucleus ${ }^{\circledR} 3$ system. A : Internal device (Nucleus 24 Contour ${ }^{\top M}$ ), B : Body-worn type speech processor (SPrintTM) , C : Ear-level speech processor ( ESPrit 3GTM) . 


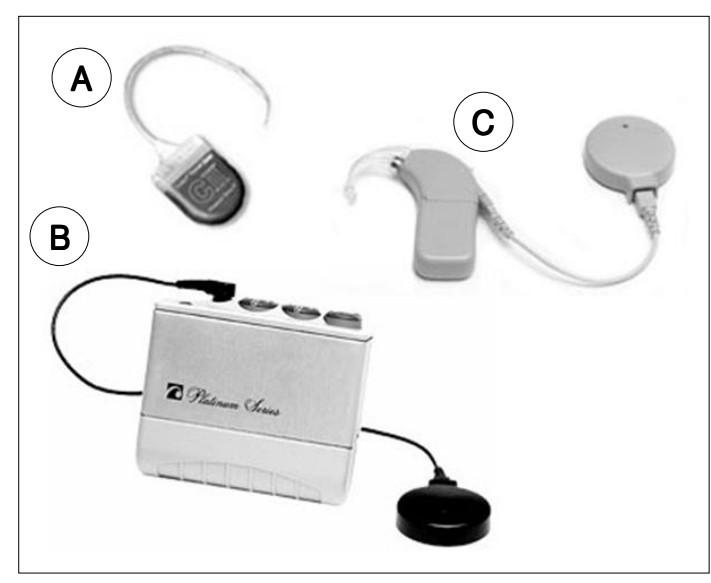

Fig. 3. The Clarion ${ }^{\circledR} C \|$ Bionic Ear'M system. A : Internal device ( CII Bionic Ear'M), B : Body-worn type speech processor (Platinum Sound Processor ${ }^{\top M}$ ), C : Ear-level speech processor ( C II BTETM).

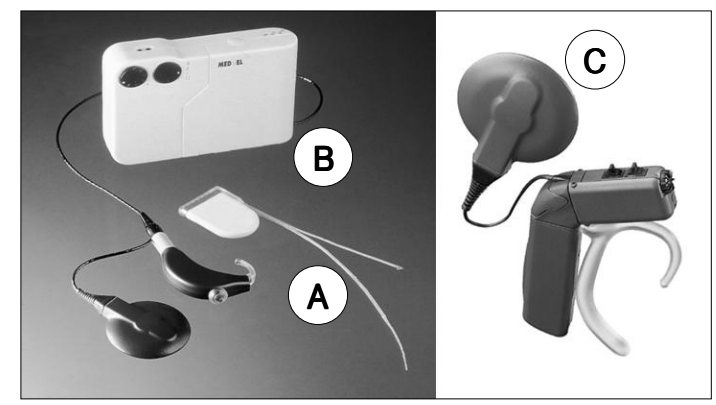

Fig. 4. Med-El COMBI40/40+ system. A : Internal device ( COMBI40/40+ TM) , B : Body-worn type speech processor ( CIS PRO+ ${ }^{T M}$ ) , C : Ear-level speech processor ( TEM$\left.\mathrm{PO}+{ }^{\mathrm{TM}}\right)$.

Clarion series, 오스트리아 Med- El사의 COMBI40/ 40+ series등이다. Nucleus 22채널 와우이식기는 1982 년 호주에서 처음으로 시술되었으며 2000년 11월에는 FDA 에 의해Nucleus 24 contour가 12개월 이상의 소 아에 대해 사용이 승인되었다. 1999년부터는 귀걸이형 (BTE) 언어처리기가 판매되었고 최근 Nucleus 24채 널 전용 귀걸이형 언어처리기인 ESPrit3G를 소개하였 다Fig. 2) . Clarion 와우이식기는 1993년에 처음 소개 되었고 2000년 11월에 18개월 이상의 소아에 대한 사 용이 FDA 승인을 받았다. Positioner를 사용하여 와우 축의 신경절 세포에 더 가까이 전극을 위치시키도록 하 였으나 2002년 와우이식술후 뇌막염의 가능한 원인으 로 지목되면서 Positioner를 사용하지 않는 모델로 환
원되었다. Clarion와우이식기의 경우 송화기와 인테나가 일체형으로 되어있어 어음처리기가 신체착용형(bodyworn type) 인 경우 귀걸이가 없다. 귀걸이형의 어음처리 기가 개발되어 있으며 최신모델은 C II Bionic ear sysem 이다Fig. 3). Med- El와우이식기는 독일 등 유럽을 중 심으로 널리 사용되는 와우이식기로 1976년에 처음 개 발되어 1991년 귀걸이형 언어처리기를 최초로 개발하 였으며 현재 주력상품인 COMBI40+ series는 2003년 3 월 12개월 이상 소아에 대한 시술을 FDA 승인받았으 며, 전용 언어처리기인 T EMPO+ 는 기본사양이 귀걸이 형이다(Fig. 4).

\section{중심 단어 : 와우이식. 진농. 적응증. 뇌수막염.}

\section{REFERENCES}

1) Park KH. History and ideal system of CI in Korea. The 9th Ajou otology symposium;2003. p.3-4.

2) Arts HA, Garber A, Zwolan TA. Cochlear implants in young children. Otolaryngol Clin North Am 2002;35(4):925-43.

3) Luntz M, Balkany T, Hodges AV, Teslische FFl. Cochlear implants in children with congenital inner ear malformations. Arch Otolaryngol Head Neck Surg 1997;123:974-7.

4) Molter DW, Pate BR, McElveen JT. Cochlear implantation in the congenitally malformed ear. Otolaryngol Head Neck Surg 1993;108(2):174-7.

5) Balkany T, Gantz BJ, Steenerson RL, Cohen NL. Systematic approach to electrode insertion in the ossified cochlea. Otolaryngol Head Neck Surg 1996;114:4-11.

6) Rauch SD, Herrmann BS, Davis LA, Nadol JB. Nucleus 22 cochlear implantation results in postmeningitic deafness. Laryngoscope 1997;107:1606-9.

7) Kim CS, Chans SO, Oh SH, Koo JW, Hwang CH, Lee HJ, et al. Outcome of cochlear implantation in postmeningitic children. Korean J Otolaryngol 2002;45:13-7.

8) Nabili V, Brodie HA, Neverov NI, Tinling SP. Chronology of labyrinthitis ossificans induced by Streptococcus pneumoniae meningitis. Laryngoscope 1999;109(6):931-5.

9) Axon PR, Temple RH, Saeed SR, Ramsden RT. Cochlear ossification after meningitis. Am J Otol 1998;19(6):724-9.

10) Waltzman SB, Scalchunes V, Cohen NL. Performance of multiply handicapped children using cochlear implants. Am J Otol 2000;21(3):329-35.

11) FDA Public Health Web Notification. Cochlear implant recipients may be at greater risk for meningitis. Updated Oct $17 ; 2002$.

12) CDC. Pneumococcal vaccination for cochlear implant candidates and recipients: updated recommendations of the advisory committee on immunization practices. MMWR Morb Mortal Wkly Rep 2003 Aug 8;52(31):739-40.

13) Balkany TJ, Hodges AV, Eshraghi AA, Butts S, Bricher K, Lingvai J, et al. Cochlear implant in children-A review. Acta Otolaryngol 2002;122:356-62. 